\section{(d) \\ CrossMark}

\title{
Association of wheeze with lung function decline in children with sickle cell disease
}

\author{
To the Editor:
}

Emerging evidence suggests that wheezing in children with sickle cell disease (SCD) is associated with higher rates of acute chest syndrome (ACS) and vaso-occlusive crises, independent of a diagnosis of asthma $[1,2]$. We investigated the relationships of longitudinal pulmonary function decline with wheeze, asthma and atopy in a cohort of paediatric patients with SCD, using the International Study of Asthma and Allergies in Childhood (ISAAC) questionnaire [3], skin prick testing (SPT) and airway nitric oxide (NO) measurements.

Approval was obtained from the Hospital for Sick Children Institutional Research Ethics Board, and written informed consent was obtained.

Children with SCD $\geqslant 6$ years of age and able to perform pulmonary function testing (PFT) were recruited from 2006 to 2011. Subjects were excluded if they had experienced an upper or lower respiratory tract infection during the 2 weeks before PFT. Patient records were reviewed to identify those with a history of ACS, defined as a hospitalisation with chest pain, dyspnoea, and new infiltrates on chest radiograph.

Fractional exhaled nitric oxide at $50 \mathrm{~mL} \cdot \mathrm{s}^{-1}\left(\mathrm{FeNO}_{50}\right)$, nasal nitric oxide (NO) (aspiration flow $330 \mathrm{~mL} \cdot \mathrm{min}^{-1}$ ), and spirometry were measured and interpreted as per published guidelines [4-7]. SPT was performed on the forearm using a Multi-Test II applicator, with 14 standardised allergenic extracts (ALK-Abelló Inc., Round Rock, TX, USA). Subjects were defined as atopic if they had a wheal of $3 \mathrm{~mm}$ or greater in diameter, compared with saline control, to any extract.

Descriptive statistics were used for demographics, disease characteristics and PFT measures. Chi-squared test was used to assess for association between categorical variables of interest. Two-way analysis of variance (ANOVA) was used to assess the association of PFT measures with the categorical covariates of interest, adjusted for sex. Linear mixed effects model with appropriate covariance structure was used to determine the rate of PFT decline with age, and to assess for associations with potential risk factors (atopy, SCD genotype, ACS, wheezing, asthma diagnosis). All p-values were two-sided, and $\mathrm{p}<0.05$ was used to indicate significant differences. Statistical analysis was performed using SAS Version 9.4 (SAS Institute Inc., Cary, NC, USA).

In total, 154 patients with SCD were included (table 1). No significant differences in PFT were seen between those reporting taking $(\mathrm{n}=12,8 \%)$ or not taking asthma medications. Individuals using asthma medications, or those with the haemoglobin ( $\mathrm{Hb}$ ) HbSS genotype or prior ACS, were not more likely to have significant bronchodilator responsiveness in forced expiratory volume in $1 \mathrm{~s}$ (FEV1), forced vital capacity (FVC), or forced expiratory flow at 25-75\% of FVC (FEF25-75). Patients with a physician diagnosis of asthma $(n=24,22 \%)$ had lower mean FEF25-75 compared with the rest of the cohort $(71.5 \%$ versus $84.0 \%$ predicted, $\mathrm{p}=0.0447)$, but otherwise similar PFT. They were not more likely to have bronchodilator responsiveness in FEV1, FVC, or FEF25-75. There was a positive association between $\mathrm{Hb}$ and FEV1 \%predicted $(\mathrm{r}=0.29314, \mathrm{p}=0.0002)$, and FVC \%predicted $(\mathrm{r}=0.27105, \mathrm{p}=0.0007)$. Univariable analysis revealed a significant impact of $\mathrm{Hb}$ on bronchodilator responsiveness in $\mathrm{FEV} 1$ and FVC $(\mathrm{OR}=1.031,95 \%$ CI 1.006-1.057, $\mathrm{p}=0.0165)$.

@ERSpublications

Wheeze in children with sickle cell disease is associated with airflow limitation and lung function decline http://ow.ly/oyZQ30fXnQs

Cite this article as: Bendiak GN, Mateos-Corral D, Sallam A, et al. Association of wheeze with lung function decline in children with sickle cell disease. Eur Respir J 2017; 50: 1602433 [https://doi.org/ 10.1183/13993003.02433-2016]. 


\begin{tabular}{|c|c|}
\hline Subjects $n$ & 154 \\
\hline \multicolumn{2}{|l|}{ Demographics } \\
\hline Age years & $12.6 \pm 3.3(6-18)$ \\
\hline Male sex $\mathrm{n}(\%)$ & $76(49 \%)$ \\
\hline \multicolumn{2}{|l|}{ Hb genotype $n(\%)$} \\
\hline $\mathrm{HbSS}$ & $106(69 \%)$ \\
\hline $\mathrm{HbSC}$ & $34(22 \%)$ \\
\hline $\mathrm{HbSB}^{+}$thal & $9(6 \%)$ \\
\hline $\mathrm{HbSB}^{\circ}$ thal & $4(3 \%)$ \\
\hline $\mathrm{HbSE}$ & $1(1 \%)$ \\
\hline History of ACS n (\%) & $56(36 \%)$ \\
\hline \multicolumn{2}{|l|}{ Pulmonary function testing } \\
\hline FVC \% predicted & $86.7 \pm 14.0(53-127)$ \\
\hline $\mathrm{FEV}_{1} \%$ predicted & $84.8 \pm 15.0(48-118)$ \\
\hline $\mathrm{FEV}_{1} / \mathrm{FVC} \%$ & $86.1 \pm 6.1(64-98)$ \\
\hline FEF $25-75 \%$ predicted & $84.4 \pm 29.9(31-261)$ \\
\hline $12 \%$ change in $F E V 1$ or FVC $n(\%)$ & $20(13 \%)$ \\
\hline $30 \%$ change in FEF $25-75 \mathrm{n}(\%)$ & $46(30 \%)$ \\
\hline \multicolumn{2}{|l|}{ ISAAC questionnaires ${ }^{\#}$} \\
\hline Physician diagnosis of asthma $\mathrm{n}(\%)$ & $24(22 \%)$ \\
\hline History of ever having wheezed $n(\%)$ & $42(39 \%)$ \\
\hline History of recent wheezing $n(\%)$ & $21(19 \%)$ \\
\hline \multicolumn{2}{|l|}{ Airway nitric oxide measurements } \\
\hline Fractional exhaled nitric oxide ppb & $17.9 \pm 15.9(2-102)$ \\
\hline Nasal nitric oxide ppb & $890 \pm 387(16-3146)$ \\
\hline \multicolumn{2}{|l|}{ Rate of decline in $\mathrm{FEV}_{1} / \mathrm{FVC}^{+}$} \\
\hline History of recent wheezing \% (95\% Cl) & $0.90(0.61-1.19)$ \\
\hline No history of recent wheezing \% $(95 \%$ Cl) & $0.33(0.22-0.44)$ \\
\hline
\end{tabular}

Data are presented as population mean $\pm \mathrm{SD}$, unless otherwise stated. Values in parentheses represent minimum/maximum ranges, unless otherwise stated. Spirometric values were derived from the Hankinson equations [6]. Hb: haemoglobin; ACS: acute chest syndrome; FVC: forced vital capacity; FEV1: forced expiratory volume in $1 \mathrm{~s}$; FEF25-75: forced expiratory flow at $25-75 \%$ of FVC; ISAAC: International Study of Asthma and Allergies in Childhood. ${ }^{\#}: \mathrm{n}=108 ;{ }^{\text {ๆ }}: \mathrm{n}=144 ;^{+}: \mathrm{n}=97$.

Of the 154 SCD subjects, 80 (52\%) were atopic by SPT. There were no differences in PFT results, rates of bronchodilator responsiveness or ACS frequency between atopic and non-atopic patients. ISAAC questionnaires were completed by 108 subjects (70\%). Among this group, 54 (50\%) were atopic according to SPT. Rates of physician diagnosis of asthma and recent/remote wheezing were not different between the atopic and non-atopic groups.

There was no relationship between $\mathrm{FeNO}_{50}$ or nasal NO and ACS history, bronchodilator responsiveness, asthma diagnosis or history of wheezing. There was no relationship between nasal NO and atopic status. However, atopic individuals had higher mean $\mathrm{FeNO}_{50}$ compared with non-atopic individuals (21.22 ppb versus $14.65 \mathrm{ppb}, \mathrm{p}=0.035)$.

Longitudinal PFT data were available for 137 subjects (after excluding those taking asthma medications), with an average of six (2-14) measurements per person. The SCD genotype HbSS was the strongest risk factor for decline in PFT after adjusting for age and sex. Neither atopy nor provided ACS history added effect on PFT decline. Of those who completed ISAAC questionnaires, 97 had longitudinal PFT data available for analysis. After adjusting for age, sex, prior ACS and SCD genotype, a history of ever having wheezed was associated with a $3.1 \%$ lower $\mathrm{FEV} 1 / \mathrm{FVC}$ ratio $(\mathrm{p}=0.0001)$ and $12.4 \%$ predicted lower FEF25-75 $(p=0.005)$ at all time points. There was no effect of asthma diagnosis, atopy or history of wheezing (recent or remote) on the rate of decline in FVC, FEV1 or FEF25-75, but a history of recent wheezing (within the past year) was a significant predictor of rate of decline in FEV1/FVC (see table 1).

To our knowledge, this is the first longitudinal study to show that in children with SCD, the clinical phenotype of wheezing is associated with more rapid PFT decline over time. This association, while seen exclusively in measures of airway obstruction, was independent of a diagnosis of asthma. A hallmark of asthma in the general population, and a key diagnostic feature, is reversible airflow limitation [8]. In this SCD cohort, $13 \%$ had significant bronchodilator responsiveness in either FEV1 or FVC, according to American Thoracic Society (ATS)/European Respiratory Society (ERS) criteria, and 30\% had an 
improvement of $\geqslant 30 \%$ in FEF25-75 following bronchodilator administration. However, using either published ATS criteria for bronchodilator response [7] or improvement of $\geqslant 30 \%$ in FEF25-75, the rates of bronchodilator responsiveness in our cohort were considerably lower than asthma rates reported in other SCD studies, in which up to $53 \%$ of participants were diagnosed with asthma [9]. When the ISAAC questionnaires from our study were reviewed, a possible explanation for these discrepancies emerged. While $22 \%$ of patients reported a physician diagnosis of asthma, 38\% had a history of wheezing, with 19\% reporting wheezing within the past year. Thus, inconsistent use of diagnostic criteria, including physician diagnosis, patient symptom report or reversible airflow limitation on PFT, may contribute to the wide variation in asthma prevalence reported in SCD populations in the existing literature [9-12].

In this cohort of paediatric patients with SCD from Toronto, half were atopic, with patient-reported wheezing and physician-diagnosed asthma rates comparable between atopic and non-atopic participants. Similar results were obtained by KNIGHT-MADDEN et al. [10], who identified a significant proportion of non-atopic asthmatic patients in their Jamaican paediatric SCD population. Mean $\mathrm{FeNO}_{50}$, a marker of eosinophilic airways inflammation and asthma, was slightly elevated in our atopic compared with our non-atopic patients, but neither was increased from normal reference values [13]. Thus, summarising our observations, the previously established links between asthma and morbidity in the SCD population may be better expressed as an association between wheezing and morbidity. A limitation of our study is a lack of assessment of additional markers of disease severity, which could help to elucidate the links between respiratory symptoms and overall SCD status.

GLASSBERG et al. [14] hypothesised that wheezing in SCD may represent an intrinsic component of SCD-related lung disease, rather than asthma, congruent with our findings, with increased capillary blood volume at least partly explaining airway obstruction in this population [15]. SCD-modifying therapies such as hydroxyurea may therefore be more appropriate than asthma therapy for treatment of the underlying causes for wheeze in these patients. This is supported by the recent observation that hydroxyurea therapy resulted in improved PFT decline in treated children with sickle cell anaemia [16]. Further study is required to establish the pathophysiology underlying wheeze and airflow limitation in children with SCD, as well as investigation into appropriate therapies that will improve lung health in these patients.

Glenda N. Bendiak ${ }^{1}$, Dimas Mateos-Corral ${ }^{2}$, Anwar Sallam ${ }^{3}$, Eshetu G. Atenafu ${ }^{4}$, Melanie Kirby ${ }^{5}$, Isaac Odame ${ }^{5}$, Peter Bikangaga ${ }^{3}$, Padmaja Subbarao ${ }^{3,6}$ and Hartmut Grasemann ${ }^{3,6}$

${ }^{1}$ Section of Respiratory Medicine, Dept of Pediatrics, Alberta Children's Hospital, Calgary, AB, Canada. ${ }^{2}$ Division of Pediatric Respiratory Medicine, Dept of Pediatrics, IWK Health Centre, Halifax, NS, Canada. ${ }^{3}$ Division of Respiratory Medicine, Dept of Pediatrics, The Hospital for Sick Children, Toronto, ON, Canada. ${ }^{4}$ Biostatistics Dept, University Health Network, Toronto, ON, Canada. ${ }^{5}$ Division of Hematology and Oncology, Dept of Pediatrics, The Hospital for Sick Children, Toronto, ON, Canada. ${ }^{6}$ Program in Physiology and Experimental Medicine, SickKids Research Institute, The Hospital for Sick Children, and University of Toronto, Toronto, ON, Canada.

Correspondence: Hartmut Grasemann, Hospital for Sick Children, 555 University Avenue, Toronto, ON, Canada M5G 1X8. E-mail: hartmut.grasemann@sickkids.ca

Received: April 212016 | Accepted after revision: June 072017

Acknowledgements: We thank the Brampton SCD Family Group for their help publicising the project, Lani Lieberman for her assistance in designing the protocol, Edwin Ho for assistance in data entry and the Paediatric Consultants at the Hospital for Sick Children for providing funding for the study.

Conflict of interest: None declared.

\section{References}

1 Glassberg JA, Chow A, Wisnivesky J, et al. Wheezing and asthma are independent risk factors for increased sickle cell disease morbidity. Br J Haematol 2012; 159: 472-479.

2 Strunk RC, Cohen RT, Cooper BP, et al. Wheezing symptoms and parental asthma are associated with a physician diagnosis of asthma in children with sickle cell anemia. J Pediatr 2014; 164: 821-826.

3 Asher MI, Keil U, Anderson HR, et al. International Study of Asthma and Allergies in Childhood (ISAAC): rationale and methods. Eur Respir J 1995; 8: 483-491.

4 American Thoracic Society/European Respiratory Society. ATS/ERS recommendations for standardized procedures for the online and offline measurement of exhaled lower respiratory nitric oxide and nasal nitric oxide, 2005. Am J Respir Crit Care Med 2005; 171: 912-930.

5 Miller MR, Hankinson J, Brusasco V, et al. Standardisation of spirometry. Eur Respir J 2005; 26: 319-338.

6 Hankinson JL, Odencrantz JR, Fedan KB. Spirometric reference values from a sample of the general U.S. population. Am J Respir Crit Care Med 1999; 159: 179-187.

7 Pellegrino R, Viegi G, Brusasco V, et al. Interpretative strategies for lung function tests. Eur Respir J 2005; 26: 948-968.

8 Reddel HK, Bateman ED, Becker A, et al. A summary of the new GINA strategy: a roadmap to asthma control. Eur Respir J 2015; 46: 622-639.

9 Bryant R. Asthma in the pediatric sickle cell patient with acute chest syndrome. J Pediatr Healthcare 2005; 19: $157-162$. 
10 Knight-Madden JM, Forrester TS, Lewis NA, et al. Asthma in children with sickle cell disease and its association with acute chest syndrome. Thorax 2005; 60: 206-210.

11 Boyd JH, Macklin EA, Strunk RC, et al. Asthma is associated with acute chest syndrome and pain in children with sickle cell anemia. Blood 2006; 108: 2923-2927.

12 Nordess ME, Lynn J, Zacharisen MC, et al. Asthma is a risk factor for acute chest syndrome and cerebral vascular accidents in children with sickle cell disease. Clin Mol Allergy 2005; 3: 2.

13 See KC, Christiani DC. Normal values and thresholds for the clinical interpretation of exhaled nitric oxide levels in the US general population: results from the National Health and Nutrition Examination Survey 2007-2010. Chest 2013; 143: 107-116.

14 Glassberg JA, Strunk R, DeBaun MR. Wheezing in children with sickle cell disease. Curr Opin Pediatr 2014; 26 : 9-18.

15 Wedderburn CJ, Rees D, Height S, et al. Airways obstruction and pulmonary capillary blood volume in children with sickle cell disease. Pediatr Pulm 2014; 49: 716-722.

16 McLaren, A, Klingel M, Behera S, et al. Effect of hydroxyurea therapy on pulmonary function in children with sickle cell anemia. Am J Respir Crit Care Med 2017; 195: 689-691. 